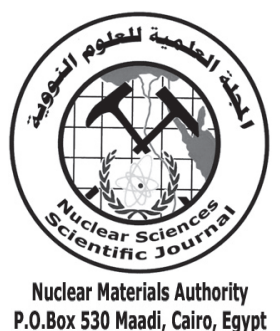

ISSN 2314-5609

Nuclear Sciences Scientific Journal

vol. 2, p 139 - 152

2013

\title{
POTENTIALITY OF URANIUM ADSORPTION AND ITS ASSOCIATED ELEMENTS FROM WASTE LABORATORY LIQUIDS USING BLACK TEA WASTE
}

\author{
ENASS M. EL-SHEIKH \\ Nuclear Materials Authority, P.O. box 530 El Maadi, Cairo, Egypt
}

\begin{abstract}
The black tea waste, representing an efficient natural ,bio-adsorbent has been applied for adsorption of some hazardous elements. Several batch wise experiments are conducted to determine the relevant factors affecting its adsorption characteristics especially for uranium. The studied factors are the effects of stirring, agitation time, $\mathrm{pH}$, solid/ liquid ratio and initial metal concentration.

The equilibrium data are found to be satisfactorily fitting to Langmuir isotherms. A maximum-metal uptake of $60.56 \mathrm{mg} / \mathrm{g}$ was observed for uranium at a solution $\mathrm{pH}$ range of 4.5-5.5. The studied elements include U, Th and REEs in the presences of some possible interfering elements. Elution of the studied interesting elements has been achieved and from their eluates proper concentrates have been prepared.
\end{abstract}

\section{INTRODUCTION}

Contamination of the environment by toxic metals from several types of both natural and industrial operations is a world wide phenomenon. Their removal by various physical, chemical or biological methods has been repeatedly attempted to overcome this problem. In the same time, the utilization of agricultural waste materials has become of vital concern as these wastes represent serious disposal problems. Numerous waste biomass sources are available and upon which several experimental adsorption studies were performed e.g. rice husk (Zulkali et al., 2006), peanut shells (Wafwoyo et al., 1999), corn cobs (Vaughan et al., 2001) saw dust ( Sciban et al., 2006),etc.

Bio-sorption of heavy metals occur upon such biomass sources as a result of physiochemical interaction-mainly ion exchange or complex formation -between metal ions and the functional groups present on the cell surface of these sources like carboxyl, amine , amide, etc. There is a considerable potential for adopting such systems in the form of used black tea waste resulting in large quantities as a waste byproduct in cafeterias as an adsorbent for the removal of hazardous metal values from aqueous solutions.

Amarasinghe and Williams (2007) reported that non treated black tea waste is a good adsorbent for the removal of $\mathrm{Cu}$ and $\mathrm{Pb}$ from waste water. Highest metal uptake attaining 48 and $65 \mathrm{mg} / \mathrm{g}$ are reported for $\mathrm{Cu}$ and $\mathrm{Pb}$, respectively. Tan (1985) has also reported that the consumed coffee powder and black tea waste were found to be able to remove substantial amounts of $\mathrm{Cu}$ (II) ions from aqueous solutions. The obtained results were found to be consistent with the fact that the $\mathrm{Cu}$ (II) uptake mechanism was due to specific ion adsorption via chelating and to a lesser degree of ion-exchange reaction.

The present work is designed to investigate the potentiality of black tea waste to adsorb some metal values from aqueous lab waste solutions as means for their recovery e.g. $\mathrm{Cu}$, $\mathrm{U}, \mathrm{Th}, \mathrm{REEs}$, etc. For this purpose several series of adsorption experiments have first been performed using proper synthetic solutions to optimize the different factors. 


\section{EXPERIMENTAL}

\section{Materials}

\section{Preparation of black tea waste}

The black tea is indeed prepared from the green tea being mainly produced from its vast plantations in Ceylon, India and Kenya. For this purpose, the green tea is subjected to poly phenyl oxidation through its fermentation. The black tea waste used for adsorption experiments in the present work has first been thoroughly washed with boiling water for the removal of soluble and colored components. The washed waste black tea is then washed with distilled water followed by washing with $5 \% \mathrm{HCl}$. Then it is dried overnight at $70{ }^{\circ} \mathrm{C}$ before storing in polyethylene bags. Acid washing is intended to keep the black tea waste away from its decomposition by various bacteria and fungi.

\section{Preparation of synthetic solutions}

Synthetic solution of uranium and other working elements have been prepared from their proper salts. Different metal solutions were thus prepared by dissolving analytical grade metal salts in distilled water or mineral acids to obtain accurate concentration as ppm $(\mathrm{mg} / \mathrm{l})$. From the latter, the working solutions were prepared by dilution to realize the required concentration. The $\mathrm{pH}$ of these solutions was measured and adjusted at $4.5 \pm 0.5$ and all the adsorption experiments run at room temperature $25 \pm 2 \circ \mathrm{C}$. The metal salts used include the nitrate salts of $\mathrm{U}, \mathrm{Cu}, \mathrm{Ca}, \mathrm{Pb}$ and $\mathrm{Th}$, the chloride salts of $\mathrm{Fe}$ and $\mathrm{Cd}$ and the hydroxide salts of $\mathrm{Ni}$ and REEs (Y and $\mathrm{Ce}$ ).

\section{Adsorption Experimental Procedure}

Batch adsorption tests are conducted by mixing of $2 \mathrm{~g}$ of the working black tea waste with $100 \mathrm{ml}$ of the different working solutions of known metal ion concentration in proper glass beakers. The prepared mixture is shaken in a mechanical shaker and a $2 \mathrm{ml}$ sample solution is periodically withdrawn from the beaker at known time intervals. Preliminary experiments have shown that adsorption is ad- equately fast and the removal rate was actually found to be negligible after $60 \mathrm{~min}$. Therefore, $60 \mathrm{~min}$ is used as the contact time for almost batch tests except in the experiments of the effect of the initial uranium concentration. At the end of each experiment, the black tea waste sample is filtered and washed to remove any fine particles before being analyzed for the adsorbed metal ions. Several series of experiments are thus conducted to determine the optimum values of the relevant factors controlling the adsorption process. As previously mentioned, The solution $\mathrm{pH}$ all the time is fixed at $4.5 \pm 0.5$ and all the experiments are conducted at room temperature $(25 \pm 2 \circ \mathrm{C})$.

On the other hand, for the determination of uranium equilibrium isotherm, the corresponding experiments are conducted by mixing $1 \mathrm{~g}$ of the working black tea waste with $50 \mathrm{ml}$ of uranium of initial concentrations ranging from 10 to $2000 \mathrm{mg} / 1$. In these experiments, each batch mixture is shaken for a contact time of up to $3 \mathrm{~h}$ to reach equilibrium . For each adsorption experiment the adsorptive capacity (qe) is determined according to the following equation;

$$
\mathrm{qe}=\mathrm{V}\left(\mathrm{C}_{0}-\mathrm{Ce}\right) / \mathrm{M}
$$

where $\mathrm{V}$ is the total volume of the solute solution ( in $\mathrm{L}$ ), $\mathrm{M}$ is the weight of adsorbent used ( $\mathrm{gm}), \mathrm{C}_{0}$ is the initial concentration of the solute $(\mathrm{mg} / \mathrm{l})$, and $\mathrm{Ce}$ is the residual equilibrium concentration of the solute $(\mathrm{mg} / \mathrm{l})$.

After studying the adsorption character of agitation solution containing $U$ and possible interferers an application experiment is conducted upon the actual working lab waste solution . For the latter, both a loading test is achieved followed by elution and precipitation of REEs , $\mathrm{U}$ and $\mathrm{Th}$. Concerning the application studies upon a working laboratories waste solution, a recovery test of $\mathrm{U}, \mathrm{Th}$ and REEs have been performed by proper elution and precipitation. 


\section{Analytical Procedures}

The various metal ions are determined using atomic absorption spectrometer (A AS) (Unicam 969, England). Meanwhile, thorium and REEs are spectrophotometerically determined by the chromogenic reagent Arsenazo-III (Merczenko, 1986), while uranium analysis in different processing stream solutions is performed by an oxidimetric titration method using ammonium metavanadate. On the other hand, the obtained REEs , $\mathrm{U}$ and Th final products have been subjected to proper analysis using both the ESEM-EDX and XRD techniques.

\section{RESULTS AND DISCUSSION}

\section{Structure of the Working Black Tea Waste}

According to Harler (1963), the ethanol insoluble black tea waste is mainly composed of cellulose, lignin and some structural proteins in different ratios . To assess the working black tea waste, a proper sample is subjected to a chemical analyses of these major components for the determination of their relative amounts. For this purpose, the procedures adopted by Tappi(1957) for cellulose lignin and carbohydrate and by Bradford, (1976) for protein have been applied. The obtained results (Table1) have indicated an almost complete similarity to that given by Harler (1963) .

Table1: Chemical composition of ethanol insoluble material extract of the working insoluble black tea waste (dry weight basis) in comparison with that of Harler (1963)

\begin{tabular}{|c|c|c|}
\hline Constituent & $\begin{array}{r}\text { Working } \\
\text { black tea } \\
\text { waste }(w t \%)\end{array}$ & $\begin{array}{r}\text { Tea waste } \\
\text { (Harler, } \\
1963), \\
(w \mathrm{t} \%)\end{array}$ \\
\hline Cell wall material & - & 38.2 \\
\hline $\begin{array}{l}\text { Hot water-soluble } \\
\text { polysaccharide and } \\
\text { proteins }\end{array}$ & 9.05 & 8.10 \\
\hline $\begin{array}{l}\text { Hot water insoluble } \\
\text { proteins }\end{array}$ & 11.22 & 10.08 \\
\hline $\begin{array}{l}\text { Lignin and structural } \\
\text { proteins }\end{array}$ & 13.17 & 12.25 \\
\hline Cellulose & 30.81 & 31.00 \\
\hline
\end{tabular}

As a matter of fact, the fresh green tea leaves contain indeed nine main compounds, namely: polyphenols (sometimes called tannins), alkaloids, protids, organic acids, glucids, lipids, cholorphylls, mineral salts and volatile substances. Each of these can be further divided into subcategories. Yang and Wang( 1996) have reported that the manufacture of the black tea from the green tea would cause changes in the chemical formulae of these components (Fig. 1).

\section{Results of Uranium Adsorption Upon Black Tea Waste}

\section{Effect of stirring state}

In order to study the effect of stirring state upon uranium adsorption efficiency, two adsorption experiments have been performed using mechanical shaking in one of them. In these experiments, $2 \mathrm{~g}$ weight of black tea waste sample is used in a S/l ratio of $1 / 50$ using a uranium solution assaying $100 \mathrm{ppm}$ and its $\mathrm{pH}$ was fixed at 4-5. After 1 hour, the black tea waste sample is filtered and the obtained filtrate is analyzed for uranium. From the obtained results, it is clear that stirring is quite important for attaining a high uranium adsorption efficiency. Thus, the latter has reached up to $95.67 \%$. while under the same conditions, the mere soaking has attained a much lower efficiency reaching only $51.13 \%$ (Fig. 2).

\section{Effect of agitation time}

For studying the effect of agitation time upon uranium adsorption efficiency, three series of experiments have been performed in which the uranium concentration was varied between 25 and $100 \mathrm{ppm}$. In these experiments, about $2 \mathrm{~g}$ of black tea waste were allowed for stirring within the uranium solution having different concentrations at a fixed $\mathrm{pH}$ of 4-5. The applied agitation time periods involved 15, 30, 60, 90, 120 and $180 \mathrm{~min}$. The obtained results are shown in Table (2) and plotted on Fig (3). From the latter results, it is noticed that by increasing the agitation time, the adsorption efficiency increases during the 
<smiles>Oc1cc(O)c2c(c1)OC(c1ccc(O)c(O)c1)C(O)C2</smiles>

(-)-Epicatechin<smiles>Oc1cc(O)c2c(c1)OC(c1cc(O)c(O)c(O)c1)C(O)C2</smiles>

(-)-Epigallocatechin<smiles>O=COC1Cc2c(O)cc(O)cc2OC1c1ccc(O)c(O)c1</smiles>

(-)-Epicatechin-3-gallate

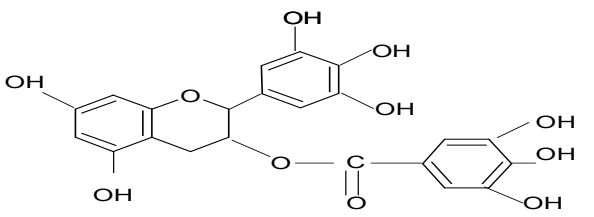

(-)-Epigallocatechin-3-gallate

\section{Major components of green tea}

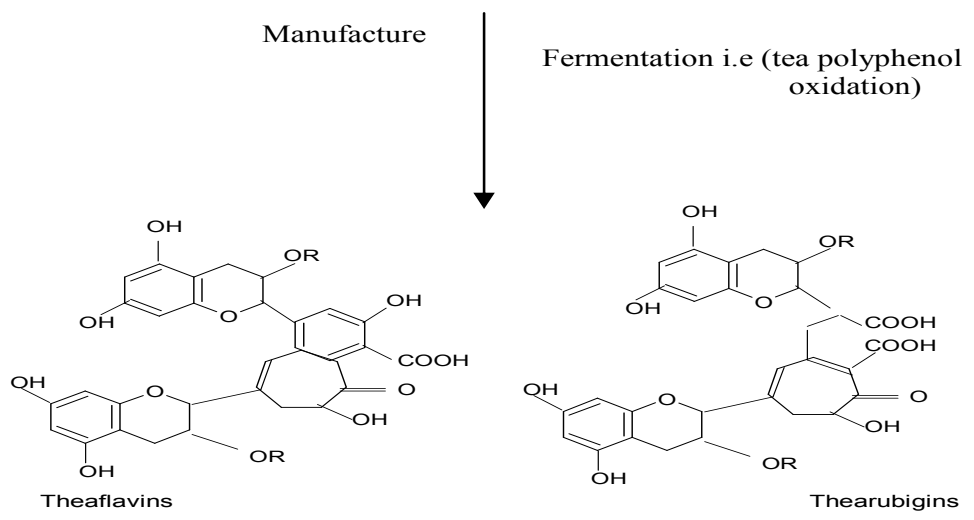

Major components of black tea

Fig. 1: The major functional groups of the green tea leaves and black tea (Yang and Wang 1996).

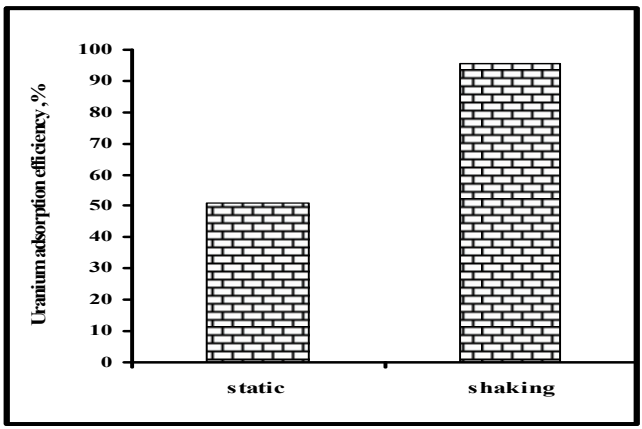

Fig. 2: Effect of stirring state on uranium adsorption efficiency by working black tea waste
Table 2: Effect of agitation time on uranium adsorption efficiency by the working black tea waste

\begin{tabular}{lllllll}
\hline Time, min & & & & & & \\
& 15 & 30 & 60 & 90 & 120 & 180 \\
\hline 25 & $90.3 \%$ & $94.57 \%$ & $97.3 \%$ & $97.44 \%$ & $99.6 \%$ & $99.999 \%$ \\
50 & $82.9 \%$ & $93.96 \%$ & $96.83 \%$ & $96.63 \%$ & $98.99 \%$ & $99.999 \%$ \\
100 & $74.37 \%$ & $91.91 \%$ & $95.73 \%$ & $96.137 \%$ & $98.12 \%$ & $99.999 \%$ \\
\hline
\end{tabular}


first one hour after which the increase in uranium adsorption is quite low. On the other hand, the adsorption efficiency decreases with increasing the uranium concentration. It is thus interesting to calculate the adsorption capacity when using contact time periods of 15 and 60 minutes and a uranium concentration of 25 and $100 \mathrm{ppm}$. The calculated adsorption capacity when using $25 \mathrm{ppm}$ uranium concentration is found to attain 1.13 and $1.21 \mathrm{mg} / \mathrm{g}$ for 15 and 60 minutes respectively. While when using 100ppm uranium concentration, the adsorption capacity is found to reach up to 3.72 and $4.79 \mathrm{mg} / \mathrm{g}$ respectively.

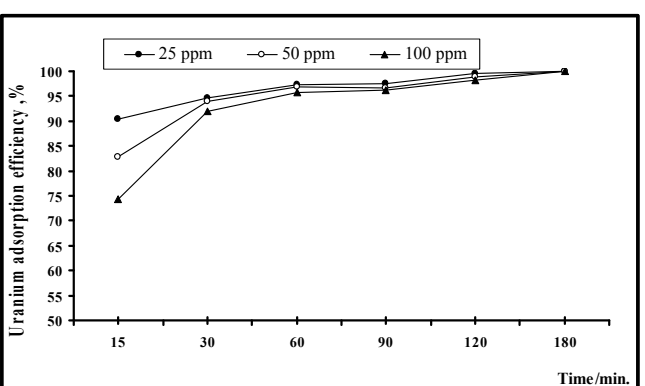

Fig. 3: Effect of agitation time upon uranium adsorption efficiency by the working black tea waste

\section{Effect of pH}

As a matter of fact, the most important parameter affecting the adsorption uptake is actually the $\mathrm{pH}$ value. Therefore, the effect of $\mathrm{pH}$ has been studied in the range of 4 to 9 using $100 \mathrm{ml}$ sample of uranium solutions assaying $100 \mathrm{ppm}, 2 \mathrm{~g}$ weight of black tea waste sample for a contact time 60 minutes. From the obtained result shown on Fig.(4), it is found that the adsorption was rapidly increased between the $\mathrm{pH} 4$ and 5. This phenomenon can be attributed to interaction between the surface charge of the adsorbent and the $\mathrm{H}^{+}$ ions concentrations in the solution. At high $\mathrm{pH}$ values the surface of the adsorbent would have much higher negative charges; resulting higher attraction of the solution cations. The obtained data are actually in agreement with comparable results obtained for other biomass materials such as the orange waste (Dhaka et al., 2005), the sago waste( Quek et al., 1998) and the saw dust (Sciban et al., 2006)etc. Obviously, the uranium adsorption onto the black tea waste would thus be optimum in the $\mathrm{pH}$ range 4.5-5.5. On the other hand, at very high $\mathrm{pH}$ values, decrease in adsorption would occur due to other effects viz hydrolysis and precipitation (Gaikwad, 2004 and Sciban et al., 2006).

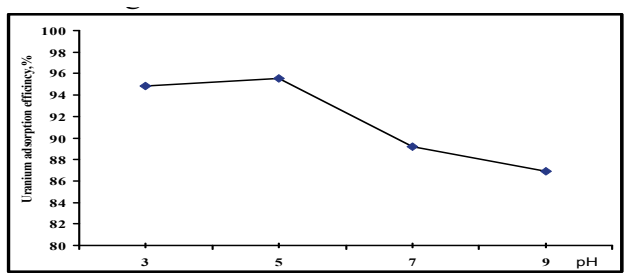

Fig. 4: Effect of $\mathrm{pH}$ upon uranium adsorption efficiency by the working black tea waste

\section{Effect of solid/ liquid ratio}

The effect of the solid liquid ratio upon the uranium adsorption efficiency is studied by agitating $2 \mathrm{~g}$ of the black tea waste in a uranium solution assaying $100 \mathrm{ppm}$ at different solid /liquid ratios; namely 1:50, 1:75, $1: 100$ and $1: 150$ for one hour. The $\mathrm{pH}$ of the uranium solution was adjusted at 4.5-5.5 .The obtained results indicated that by increasing the liquid /solid ratio, the uranium adsorption efficiency would decrease. The latter is found to decrease from 95.7 to $86.75 \%$ when using a solid liquid ratio of $1 / 50$ to $1 / 150$ respectively (Fig. 5 ).

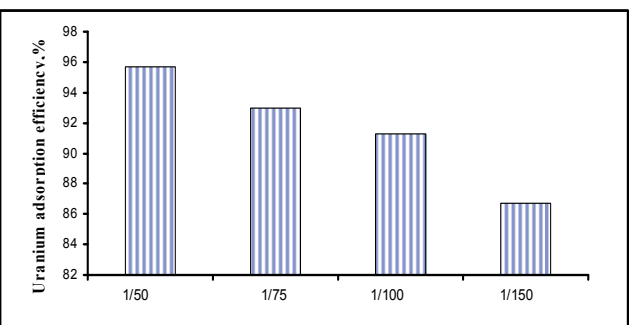

Fig. 5 :Effect of solid/ liquid ratio on uranium adsorption efficiency by the working black tea waste

\section{Effect of initial uranium concentration}

The effect of the initial uranium concentration upon the adsorption capacity of the 
working black tea waste is studied by contacting a $2 \mathrm{~g}$ fixed mass of black tea waste with uranium solution having different concentrations ranging from 10 to $2000 \mathrm{ppm}$. In these experiments a fixed temperature of $\approx 25^{\circ} \mathrm{C}$ is used beside an initial $\mathrm{pH}$ range of 4.5 to 5.5 and solid/liquid ratio of $1 / 50$, while using a contact time of $3 \mathrm{~h}$ to ensure the attainment of the equilibrium state. Plotting the obtained relationship between the uranium concentration and its adsorption capacity was found to be non- linear (Fig 6). In other words, a maximum adsorption capacity of about $60 \mathrm{mg} / \mathrm{g}$ has been attained when using a uranium solution assaying $\geq 1500 \mathrm{ppm}$.

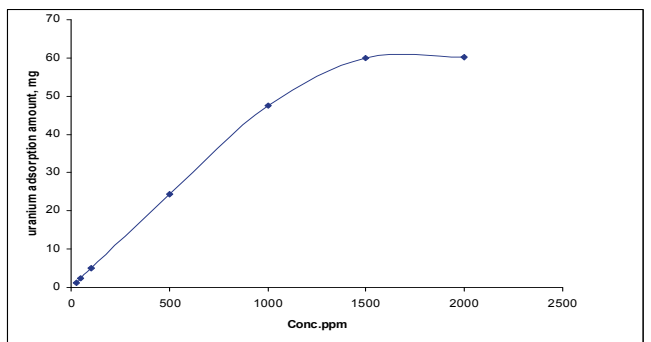

Fig. 6: Effect of initial uranium concentration upon the adsorption capacity of the working black tea waste

On other hand, it is found greatly beneficial in the present work to determine the adsorption isotherm according to langmuir and Freundlich equations. The purpose is describing the adsorption mechanism for the interaction of uranium ion on the working adsorbent surface and to express its surface properties and its affinity towards the uranium ions.

\section{Applicability of equilibrium isotherm \\ Langmuir adsorption isotherm}

Langmuir isotherm (L-shaped) model is developed by Irving Langmuir in 1918 described as the ideal localized monolayer model. This isotherm represents the equilibrium distribution of metal ions between the solid and liquid phases. The following equation can be used to model the adsorption isotherm:

$$
q=\frac{q \max \cdot b \cdot c e}{1+b \cdot C e}
$$

where $\mathrm{q}$ is the milligrams of metal accumulated per gram of the sorbent, $\mathrm{Ce}$ is the metal residual concentration in solution; qmax is the maximum specific uptake corresponding to the site saturation and $\mathrm{b}$ is the ratio of adsorption and desorption rates (Chong and Volesky, 1995).

The Langmuir isotherm is based on these assumptions (Langmuir, 1918):

- Metal ions are chemically adsorbed at a fixed number of well defined sites.

- Each site can hold only one ion.

- All sites are energetically equivalent.

- There is no interaction between the metal ions.

When the initial metal concentration rises, adsorption increases while the binding sites are not saturated. The linearized Langmuir isotherm allows the calculation of adsorption capacities and the Langmuir constants and is equated by the following equation.

$$
\mathrm{Ce} / \mathrm{q}=1 /(\mathrm{qmax} \cdot \mathrm{b})+\mathrm{Ce} / \mathrm{qmax}
$$

The linear plots of Ce/q vs Ce show that adsorption follows the Langmuir adsorption model.

The essential characteristics of the Langmuir isotherms can be expressed in terms of a dimensionless constant separation factor or equilibrium parameter, RL, which is defined as:

$$
\mathrm{RL}=1 /(1+\text { b.q max })
$$

where $\mathrm{b}$ is the Langmuir constant and $\mathrm{C}_{\mathrm{o}}$ is the initial concentration of metal ions in the solution. The RL value indicates the shape of isotherm. According to Metcalf and Eddy, (2003), RL values if between $(0-1)$ indicate favourable adsorption, if equal to (1) indicate linear adsorption and if above (1) indicate unfavourable adsorption.

From plotting the obtained data Using Langmuir equation, it is found that the relation Ce/qe vs is clearly linearized (Fig. 7 ). The Langmuir constant "q max" measures the monolayer adsorption capacity of the black tea waste and is found to attain $60.56 \mathrm{mg} / \mathrm{g}$ .The Langmuir constant " $b$ " (denotes adsorption energy) which was obtained as 0.173 
$1 / \mathrm{mg}$. The determined high coefficient value $\left(r^{2}=0.999\right)$ thus indicates a good agreement between the experimental values and the isotherm parameters and also confirms the monolayer adsorption uptake of the black tea waste surface (Table 3). The dimensionless parameter of "RL" (measures the adsorption favorability) is found to attain 0.0871 (i.e. $0<\mathrm{RL}<1$ ) confirming the favorability of the adsorption process for the uranium removal using the black tea waste. It is also found that when the RL value approaches to zero the irreversible adsorption was favored.

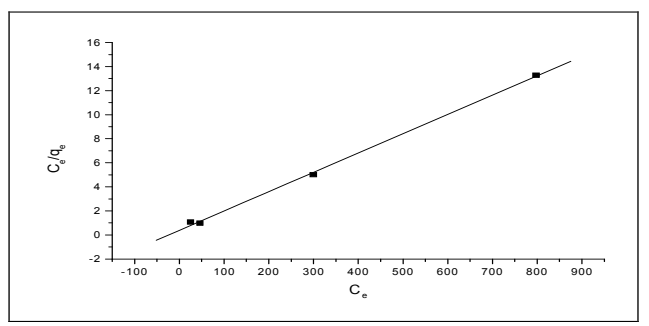

Fig. 7:Linear form of Langmuir model for uranium adsorption on the working tea waste

Table 3: Langmuir and Freundlich isotherm constants for uranium uptake by the working black tea waste at room temperature

\begin{tabular}{|c|c|c|c|c|c|c|c|}
\hline \multirow[t]{2}{*}{ Metal } & \multirow[t]{2}{*}{ Adsorbent } & \multicolumn{3}{|c|}{$\begin{array}{l}\text { Langmuir model } \\
\text { parameters }\end{array}$} & \multicolumn{3}{|c|}{ Freundlich model parameters } \\
\hline & & $\begin{array}{r}q \max \\
(\mathrm{mg} / \mathrm{g})\end{array}$ & $\begin{array}{r}\text { b } \\
(\mathrm{mg} / \mathrm{L})\end{array}$ & $\mathrm{R}^{2}$ & $1 / n$ & $\begin{array}{r}\mathrm{K}_{\mathrm{f}} \\
(\mathrm{mg} / \mathrm{g}) \\
\end{array}$ & $\mathrm{R}^{2}$ \\
\hline Uranium & $\begin{array}{r}\text { Black tea } \\
\text { waste }\end{array}$ & 60.65 & 0.173 & 0.999 & 1/0.20684 & 17.14 & 0.9 \\
\hline
\end{tabular}

\section{Freundlich adsorption isotherm}

The Freundlich isotherm is the earliest known relationship describing the sorption equilibrium. This fairly satisfactory empirical isotherm which can be used for non-ideal sorption and is expressed by the following equation (Metcalf and Eddy, 2003):

$$
\mathrm{q}=\mathrm{KfCe}^{1 / \mathrm{n}}
$$

where $\mathrm{Ce}$ is the equilibrium concentration $(\mathrm{mg} / \mathrm{l}), \mathrm{q}$ is the amount adsorbed (mg/g) and $\mathrm{Kf}$ and $\mathrm{n}$ are constants incorporating all parameters affecting the adsorption process, such as adsorption capacity and intensity respectively.
The linearized forms of Freundlich adsorption isotherm and which used in the present work to evaluate the obtained sorption data is as follows:

$$
\log q_{\mathrm{e}}=\log K_{\mathrm{f}}+\frac{1}{n} \log C_{\mathrm{e}}
$$

Where according to Kadirvelu and Namasivayam (2000) n values between 1 and 10 represent beneficial adsorption.

Both the Freundlich constants $\mathrm{Kf}$ and $\mathrm{n}$ are obtained by plotting log qe versus $\log \mathrm{Ce}$ (Fig. 8). It is thus found that the determined coefficient of Freundlich isotherm model for working black tea waste attain 0.9 which is lower than that of Langmuir isotherm model. Accordingly, it can be concluded that the obtained experimental data has actually been fitted to Langmuir isotherm and not to that of Freundlich (Table 3).

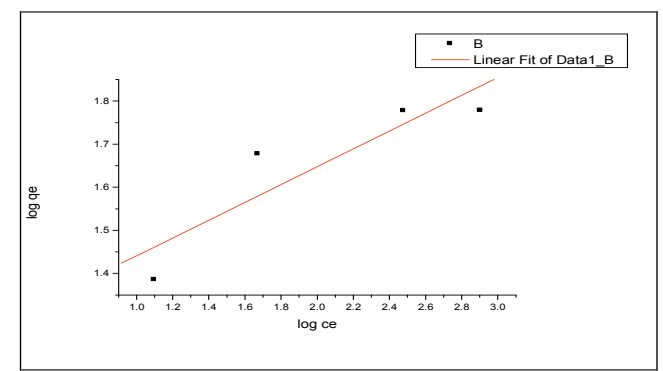

Fig. 8: Freundlich isotherm model for the uranium adsorption on the working black tea waste

\section{Loading and Elution Characteristics of a Synthetic Solution}

A proper solution of some elements that might be associated with uranium e.g. $\mathrm{Cd}, \mathrm{Pb}$, $\mathrm{Ni}, \mathrm{Fe}, \mathrm{Th}, \mathrm{Cu}, \mathrm{Ca}$ besides $\mathrm{Ce}$ and $\mathrm{Y}$ is prepared from their respective solutions, thus assaying a total of $100 \mathrm{ppm}$. In other words, the prepared solution of ten studied elements would assay $10 \mathrm{ppm}$ of each of its components.

\section{Loading characteristics of the synthetic solution}

An adsorption experiment upon the working black tea waste was then performed by stirring in the prepared synthetic solution for 
one hour at a solid liquid ratio of 1:50.The $\mathrm{pH}$ of the solution is first adjusted at $\mathrm{pH} 4.5-5.5$. The obtained adsorption results are calculated and shown in Table (4) using the following equation:

Adsorption capacity as $\mathrm{mg} / \mathrm{g}=\mathrm{V}\left(\mathrm{C}_{0}-\mathrm{Ce}\right) / \mathrm{M}$,

where $\mathrm{V}$ is the total volume of the solute solution (L),M is the weight of the adsorbent used $(\mathrm{gm}), \mathrm{C}_{0}$ is the initial concentration of the solute $(\mathrm{mg} / \mathrm{l})$ and $\mathrm{Ce}$ is the residual concentration of the solute $(\mathrm{mg} / \mathrm{l})$.

Table 4: Adsorption levels of $U$ and its associated elements $\mathrm{mg} / \mathrm{g}$ from the synthetic solution on the working black tea waste

\begin{tabular}{lrrr}
\hline Elements & $\begin{array}{r}\text { Adsorption } \\
\text { level } \mathrm{mg} / \mathrm{g}\end{array}$ & Elements & $\begin{array}{r}\text { Adsorption } \\
\text { level } \mathrm{mg} / \mathrm{g}\end{array}$ \\
\hline $\mathrm{Pb}$ & $\mathbf{0 . 4 8}$ & $\mathrm{Cd}$ & $\mathbf{0 . 4 1}$ \\
$\mathrm{Cu}$ & $\mathbf{0 . 3 9}$ & $\mathrm{Ni}$ & $\mathbf{0 . 3 9}$ \\
$\mathrm{Fe}$ & 0.40 & $\mathrm{Th}$ & 0.34 \\
$\mathrm{Ca}$ & 0.50 & $\mathrm{Ce}$ & 0.39 \\
$\mathrm{U}$ & 0.39 & $\mathrm{Y}$ & 0.31 \\
\hline
\end{tabular}

From these results it is indicated that the working black tea waste has the ability to adsorb the studied elements according to the following order of preference $\mathrm{Ca}>\mathrm{Pb}>\mathrm{Cd}>$ $\mathrm{Fe}>\mathrm{Ni} \geq \mathrm{Cu} \geq \mathrm{U} \geq \mathrm{Ce} \geq \mathrm{Th}$ and $\mathrm{Y}$. The adsorption level of these elements ranges from $0.31 \mathrm{mg} / \mathrm{g}$ for $\mathrm{Y}$ to $0.5 \mathrm{mg} / \mathrm{g}$ for Ca. This order might be interpreted as due to the size of ionic species of these elements and/or the charge assumed by these species.

\section{Elution characteristics of the loaded REEs,} Th and $U$

To study the elution characteristics, interest has been limited to the REEs, uranium, and thorium representing hazardous' materials. The loaded black tea waste obtained from the previously mentioned synthetic solution of the 10 studied elements is thus subjected to elution studies of the three mentioned elements. For this purpose, two eluants have been used; namely an alkali solution for the REEs and an acidified $\mathrm{NaCl}$ solution for both uranium and thorium.

\section{Alkali elution of the REEs}

Three alkali elution experiments have been batchwise performed at a S/1 ratio of $1 / 100$ using $\mathrm{Na}_{2} \mathrm{CO}_{3} / \mathrm{NaHCO}_{3}$ solution of $150 \mathrm{~g} / \mathrm{l}$ total concentration at different ratios of either. In these experiments a stirring time of 15 minute has been used at room temperature. From the obtained results shown in Table (5) and plotted on Fig. (9), it is indicated that the sodium carbonate/sodium bicarbonate solution ratio of $2 / 1$ has yielded up to $99.2 \%$ elution efficiency of the loaded REEs. Analysis of both uranium and thorium has shown that under these condition, their elution efficiencies have only been 0.52 and $0.64 \%$ respectively.

Table 5: Elution efficiency of the loaded REEs from the black tea waste using sodium carbonate /sodium bicarbonate eluent

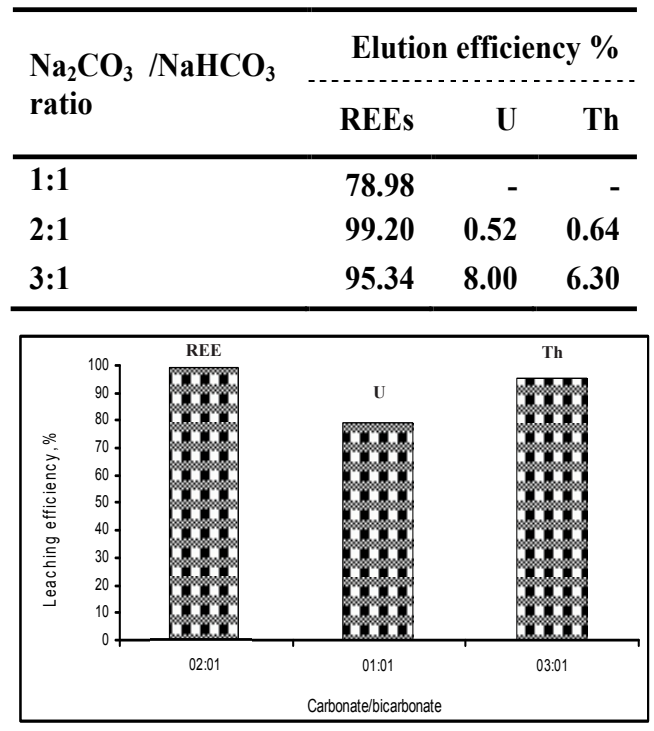

Fig. 9: Elution efficiency of the loaded REEs from the black tea waste using sodium carbonate and sodium bicarbonate eluent

\section{Salt elution of uranium and thorium}

After elution of the REEs , the elution of still loaded uranium and thorium has also been actually batchwise achieved (S/1 ratio 1/100) using $\mathrm{NaCl}$ acidified solution by sulfuric acid to the extent of $0.15,0.25$ and $0.35 \mathrm{M}$. (ELSheikh, 2006) at room temperature for 15 
minutes. From the obtained results shown Table(6) and plotted on Fig.(10), it is clearly evident that the adopted acidified salt solutions are quite efficient for elution of both uranium and thorium. Thus using $1 / 0.15$ salt /acid molar ratio, the elution efficiencies of both uranium and thorium have attained up to 95.2 and $94.1 \%$ respectively. Increasing the acid molarity to 0.35 result in almost complete elution namely; 98.9 and 97.14 for uranium and thorium respectively.

Table 6: Elution efficiency of the loaded uranium and thorium using acidified sodium chloride solution

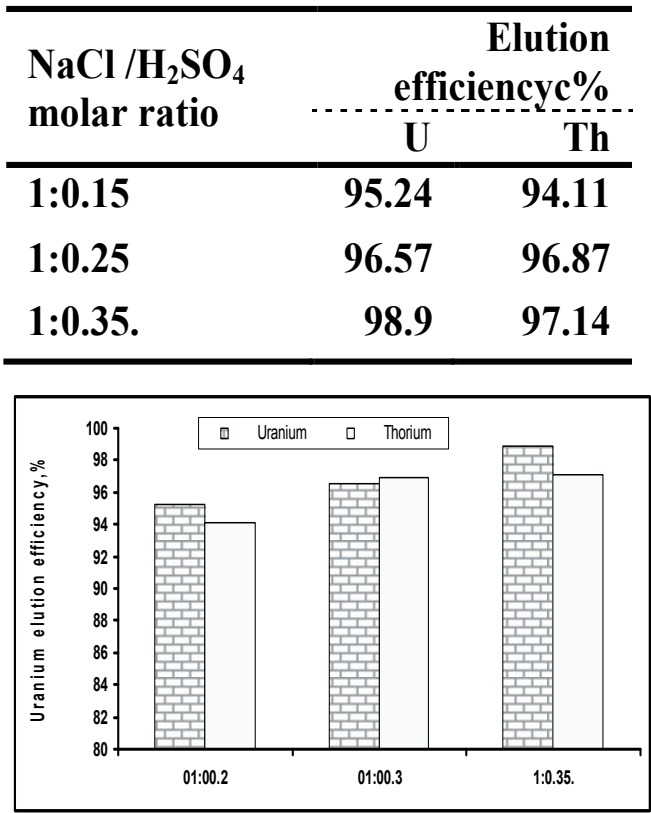

Fig. 10: Elution efficiency of the loaded uranium and thorium from black tea waste using sodium chloride and sulfuric acid in different molar ratios

Loading and Elution Characteristics of Lab Waste Solution

\section{Loading characteristics of the lab waste solution}

As a matter of fact, the specification of the black tea waste is actually considered as an important factor in determining its capacity in removing elements from different media . For practically testing the working black tea waste, it is applied upon an actual lab waste solution whose chemical composition is summarized in Table (7) .Accordingly, about 500 $\mathrm{ml}$ of this lab waste is stirred with $10 \mathrm{~g}$ of the working black tea waste for one hour, after adjusting its $\mathrm{pH}$ at 4.5-5.5. At the end of the experiment the solution is analyzed for the remaining amounts of the study elements. Their adsorption efficiencies have been calculated as shown in the mentioned table.

Table 7:Chemical composition of the tested lab waste solution and adsorption efficiency of its element

\begin{tabular}{lrr}
\hline Elements & $\begin{array}{r}\text { Conc. } \\
\text { g/l }\end{array}$ & $\begin{array}{r}\text { Adsorption } \\
\text { efficiency } \%\end{array}$ \\
\hline P & 11.4 & 99.12 \\
Na & 3.36 & 89.40 \\
S & 6.31 & 95.76 \\
Ca & 0.12 & 91.66 \\
U & 0.033 & 93.03 \\
REEs & 0.393 & 91.85 \\
Th & 0.040 & 75.00 \\
\hline
\end{tabular}

To interpret the adsorption mechanism it has been indicated that the cellulose materials ( black tea waste) has indeed been modified to act as a natural adsorbent for treating different waste media. For this purpose and as previously mentioned, the working black tea waste has only been modified via a mineral acid treatment at room temperature $\left(25 \pm 1^{\circ} \mathrm{C}\right)$ creating certain suitable characteristics. The latter could be summarized as follows:

-Pores in the cellulose fibers are indeed naturally present and can also be generated during chemical and mechanical treatments (Park et al., 2006). An EDAX photograph obtained using the Scanning Electron Microscope (SEM) clearly indicates the mentioned pores (Fig. 11a).These pores have actually been filled after the treatment of the black tea waste with the actual lab waste ( Fig. 11b). The EDAX analytical data of the native black tea waste i.e before treatment and shown in ( Fig.12a) demonstrate the absence of any radioactive elements (U and /or Th) or REEs in 
its pores . On the other hand, the EDAX analytical data of the black tea waste treated by actual lab waste clearly indicate the presences of theses elements, Fig. (12b).

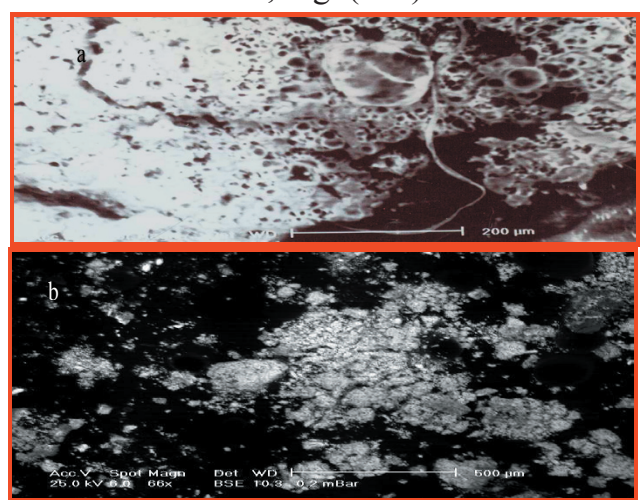

Fig. 11a,b: ESEM photos showing the working black tea waste before (a) and after (b) mixing with studied lab waste solution

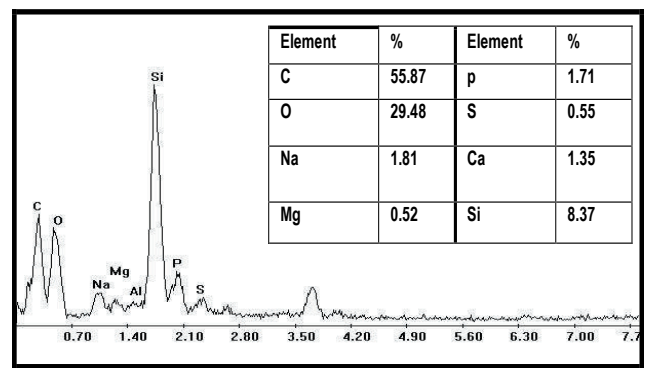

Fig 12a: ESEM - EDAX analysis of the working black tea waste before its treatment with the studied lab waste solution

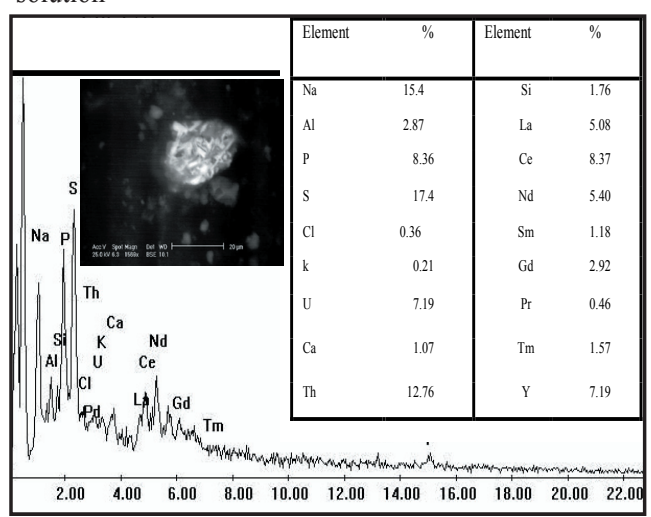

Fig.12b: ESEM- EDAX analysis of adsorbed uranium, thorium and REEs element on the black tea waste
-Cellulose is considered as a high uniform polyacetal containing three reactive hydroxyl groups being called a hydro glucose unit. Based on this molecular structure, the ordered hydrogen bond system forms various types of super molecular semi crystalline structure, which are essential for natural functions and commercial applications e.g. cellulosic fibers. Elements are known to interact with the cellulose surface through one or both faces of the cellulose-binding domain and the cellulose proximal surface of the catalytic domain (McCarter et al., 2002; Linder and Teeri, 1997).

-Acids and especially the mineral acids have an important effect on the cellulosic material where they exert an effect upon its physical properties. The latter are represented by their swelling besides acquiring higher hygroscopic as well as greater reactivity towards adsorption reactions (Mobarak et al., 1985).

-Improvement in both pyrolysis properties as well as dimension stability(Rowell, 1984).

-Finally it is interesting to refer to the fact that preparation of the black tea waste from the green tea is greatly advantageous where it becomes highly enriched in the theaflavins and the arubigens having sevseral $\mathrm{COOH}^{-}, \mathrm{COOR}-$ and $\mathrm{OH}$ moieties which would play both as anion and cation exchange compounds.

\section{Elution characteristics of the loaded REEs, $\mathrm{U}$ and Th}

As mentioned above, the elution of REEs, $\mathrm{U}$ and $\mathrm{Th}$ from the black tea waste loaded from the prepared synthetic solution is proceeded through two steps; the REEs were first eluted followed by the simultaneous elution of both $U$ and Th. Similary elution of the black tea waste loaded from the actual lab waste is undertaken using the previously mentioned conditions. Thus the working loaded black tea waste is firstly conducted with $15 \% \mathrm{Na}_{2} \mathrm{CO}_{3}$ $/ \mathrm{NaHCO}_{3}(2: 1)$ to elute the loaded REEs with an elution efficiency of $95 \%$. In the next elution step a mixture of sodium chloride solution and sulfuric acid in the molar ratio 1:0.35 
has led to almost complete elution of $U$ and Th with an efficiency of 98.7 and $97.1 \%$ respectively.

\section{Prepartion of the REEs, $U$ and Th Concen- trates}

To prepare a proper concentraties of the three intersting elements eluted from actual lab waste solution namely; REEs, $U$ and Th,it is found convenient to apply two precipitation techeniques. The REEs have been first precipitate as their hydroxides with few drops of conc. $\mathrm{HCl}$ till $\mathrm{pH}$ 6-7. The obtained precipitate is checked by an EDAX analysis and is shown on Fig.(13) which clearly indicates that it assays about $90 \%$ REEs including about $65 \%$ La,Ce and Nd while Gd, Dy, Er and $\mathrm{Yb}$ about $15 \%$ beside Lu content of $1.86 . \%$

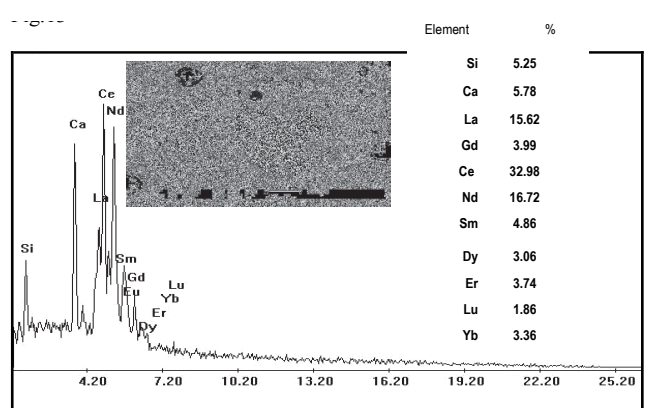

Fig. 13: ESEM-EDAX analysis of the prepared REEs concentrate

In the next elution step, uranium and thorium being simultaneously eluted, have been seperated by selective preciptation where Th was recovered as its oxalate adding an excess amount of $10 \%$ oxalic acid at $\mathrm{pH} 1-2$. The obtained thorium oxalate concentrate is filtered, dried and subjected to XRD analysis and is found to conforim with the Card No. 11-903 ( Fig. 14).

$$
\mathrm{Th}^{+4}+(\mathrm{COOH})_{2} \longrightarrow \mathrm{Th}\left(\mathrm{C}_{2} \mathrm{O}_{4}\right)_{4}
$$

The oxalate filtrate containing the eluted uranium has first been properly heated to decompose oxalate remaining in the solution whose presence would prevent uranium precipitation. After cooling the $\mathrm{pH}$ of the eluate is adjusted to 5.8 using $5 \% \mathrm{NH}_{4} \mathrm{OH}$ where uranium is precipitated. After drying, the obtained uranium diuranate concentrate is subjected to EDAX analysis (Fig. 15). From the latter it is found that uranium assay up to about $94 \%$.

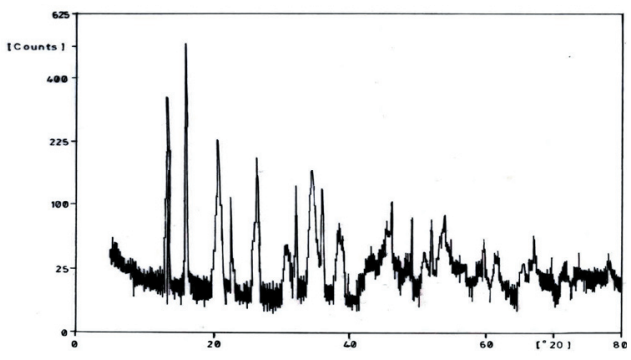

Fig. 14: XRD chart of the prepared thorium oxalate concentrate

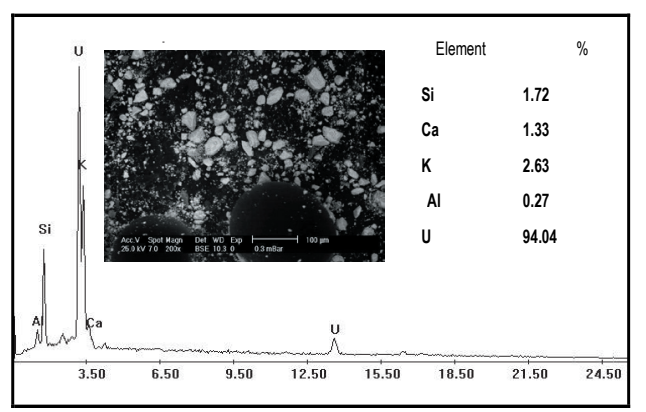

Fig.15: ESEM-EDAX analysis of the prapered ammonium diuranate concentrate

\section{Durability (Life Time) of the Black Tea Waste}

A solution of about $500 \mathrm{ml}$ sample of the working actual lab waste solution containing U,Th and REEs beside some associated elements is contacted with $10 \mathrm{~g}$ of the working dry black tea waste for one hour, after adjusting the $\mathrm{pH}$ at 4.5-5.5. The adsorption efficiency of the three working elements is calculated before being properly eluted as previous mentioned. Both the loading and elution processes are then repeated for several times using the same black tea waste sample under the same studied conditions. The purpose was to investigate the durability of the black tea waste. From the obtained result summarized in Table (8), it is clearly evident that by repeated cycling both the loading and elution efficiencies have progressively been decreased .After the $7^{\text {th }}$ cycle, the working tea waste sample has 
been completely deteriorated . This relatively short life time of the working black tea waste may be due to its pretreatment procedure .In other words, the $\mathrm{HCl}$ treatment might have affected the amount of lignin in its structure, beside its possible hydrolysis during adsorpation and /or elution processes .

Table 8: Durability of the black tea waste via 7 adsorption and elution cycles for the REEs, $\mathrm{U}$ and Th

\begin{tabular}{lcrrrrr}
\hline $\begin{array}{l}\text { Cycle } \\
\text { number }\end{array}$ & \multicolumn{2}{c}{ Adsorption efficiency, $\%$} & \multicolumn{2}{c}{ Elution efficiency $\%$} \\
\hline 1 & REEs & U & Th & REEs & U & Th \\
\hline 2 & 75.00 & 93.03 & 91.85 & 95.00 & 98.70 & 97.10 \\
3 & 73.50 & 91.76 & 89.18 & 92.40 & 96.50 & 94.44 \\
4 & 67.39 & 84.19 & 81.82 & 81.96 & 85.60 & 83.41 \\
5 & 55.84 & 69.77 & 67.80 & 74.54 & 77.86 & 75.86 \\
6 & 44.13 & 55.14 & 53.58 & 53.17 & 54.98 & 54.18 \\
7 & 18.53 & 23.18 & 22.50 & 32.78 & 33.90 & 33.40 \\
8 & 9.04 & 11.34 & 11.00 & 20.45 & 21.15 & 20.00 \\
& \multicolumn{3}{c}{ Complete deterioration of the working sample } \\
\hline
\end{tabular}

\section{CONCLUSION}

The efficiency of the black tea waste for adsorption of different hazardous elements has been properly increased through its pretreatment with a dilute solution of $\mathrm{HCl}$.The relevant adsorption factors have actually been optimized using two synthetic solutions viz a separate $U$ solution and other solution of $\mathrm{U}, \mathrm{Th}, \mathrm{Ce}$ and together with other possible interferents . The obtained results are then applied upon an actual lab waste solution containing U( $33 \mathrm{ppm}$ ), Th ( $40 \mathrm{ppm}$ ) and REEs ( 393 ppm ) beside some other elements. The former have almost been completely eluted using $\mathrm{Na}_{2} \mathrm{CO}_{3} / \mathrm{NaHCO}_{3}$ solution for the REEs, while an acidified $\mathrm{NaCl}$ solution is used for elution of both $U$ and $T h$. The eluted elements have finally been recovered by proper precipitation procedures to obtain suitable concentrate in a manner to represent important added values. The obtained results used to formulate a working flowsheet (Fig.16) for the treatment of hazardous lab waste solutions for removal of their contents of the REEs, $\mathrm{U}$ and Th.

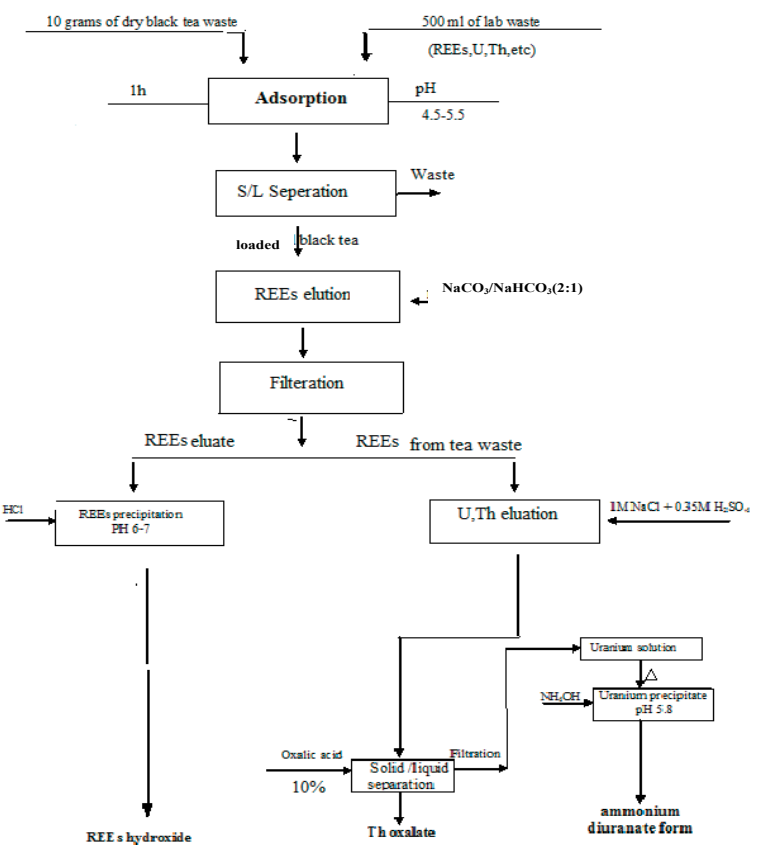

Fig. 16: A formulated flow sheet for the recovery of the REEs ,uranium and thorium from hazardous lab waste using black tea waste 


\section{REFERENCES}

Amarasinghe, B.M., and Williams, R.A.,2007. Tea waste as a low cost adsorbent for the removal of $\mathrm{Cu}$ and $\mathrm{Pb}$ from wastewater. Chem. Eng. J., $132,299-309$.

Bradford, A.M.,1976. c.f. Christian, G. HPLC Tips and Tricks. Great Britain at the Iden Press, Oxford , 1990 .

Chong, K.H., and Volesky ,B., 1995. Description of metal biosorption equilibria by Langmuir-type models. Biotechn. Bioeng., 47, no. 4, 451460.

Dhakal, R.P.; Ghimire, K.N.; Inoue, K.,2005. Adsorptive separation of heavy metal from an aquatic environment using orange waste. Hydrometallurgy, 79 ,182-190.

El-Sheikh, E.M.,2006. Geochemical studies and uranium minerals concentration using organic surfactants from radioactive syenite rocks , El-Grra El-Hamra, Tushki area, South Western Desert. Ph.D. Thesis ,Fac. Sci. ,Ain Shams Univ. , Egypt, 125p.

Gaikwad, R.W,2004. Removal of $\mathrm{Cu}$ (II) from aqueous solution by activated charcoal derived from coconut shell . Agric. Food Chem. ,ISSN $1579-4377$

Harler, C.R., 1963.Tea Manufacture'. New York. Oxford Univ. Press. HUANG. C.P., ELLIOTT, H. 108p.

Kadirvelu, K., and Namasivayam, C. A., 2000. Agricultural by-products as metal adsorbents; sorption of lead (II) from aqueous solutions onto coir-pith carbon. Enviro. Technology, 21, no. 10, 1091-1097.

Langmuir, I.,1918. The Adsorption of Gases on Plane Surfaces of Glass, Mica and platinum. Amer. Chem. Soc., 40, no. 9, 1361 - 1403.

Linder, M. , and Teeri, T.,1997. The roles and function of cellulose-binding domains. J. Biotechnology ,57, 15-28.
McCarter, S.L; Adney, W.S. ; Vinzant, T.B.; Jenning, E.;Eddy, F.P.; Decker, S.R.; Baker, J.O. ; Sakon, J., and Himmel ,M.E.,2002. Exploration of Cellulose Surface-Binding Properties of Acidothermus cellulolyticus Cel5A by SiteSpecific Mutagenesis. Appl. Biochem. Biotechn., 98-100, 273-283.

Merczenko,Z.,1986. Separation and Spectrophotometric Determination of Elements. Harwood, New York, 708 p.

Metcalf, and Eddy,2003. Wastewater engineeringtreatment and reuse, 4th ed., McGraw-Hill”, New York, USA, ISBN 0-07-041878-0.

Mobarak, F.M.;Nada, A.M.A., and Fahmy, Y.,1985. Gemischte partielle xanthogenierung und karboxymethlierung von lintern und holzzellstoff zwecks papier herstellung, Cellul. Chem. Technol.,19,97-102 .

Park, S.; Venditti, R.; Jameel, H., and Pawlak, J.,2006. Changes in pore size distribution during the drying of cellulose fibers as measured by differential scanning calorimetry. Carbohydrate Polymers, 66 , 97-103.

Quek, S.Y.; Wase, D.A.J., and Forster, C.F., 1998. The use of sagowaste for the sorption of lead and copper. Water SA, 24 (3), 251-256.

Rowell, R.M.,1984. The chemistry of solid wood, advanced in chemistry series No.20. Amer. Chem. Soc., Washington, D.C.

Sciban, M.; Kalasnja, M., and Skrbic, B.,2006. Modified softwood sawdust as adsorbent of heavy metal ions from water, J. Hazard. Mater. , 136 (2), 266-271.

Tan , W.T.,1985. Copper(II) Adsorption by Waste Tea Leaves and Coffee Powder. Pertanika ,8(2), $223-230$. 
Tappi,1957. Technical Association of the pulp and paper Industry,www. Tappi, Org/Indey asp.

Vaughan, T.; Seo, C.W, and Marshall, W.E,2001. Removal of selected metal ions from aqueous solution using modified corncobs. Bioresour. Technol.,78,133-139.

Wafwoyo, W.; Seo, C.W.; Marshell, W.E.,1999. Utilization of peanut shells as adsorbents for selected metals. J. Chem. Technol. Biotechnol., $74,1117-1121$.

Yang Chung, S., and Zhi-Yuan Wang, 1996. The Tea Man- The Chemistry of Tea, Tea and Cancer.

Zulkali, M.M.D. ; Ahmad, A.; Norulakmal, N.H ., and Oryza sativa, L.,2006.husk as heavy metal adsorbent; optimisation with lead as model solution. Bioresour. Technol.,97, 21-25.

\section{أمكانيه امتصاص اليورانيوم و العناصر المصاحبة من مخلفات المعمل السائلة باستخدام نفايات الثاي الأسود

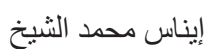

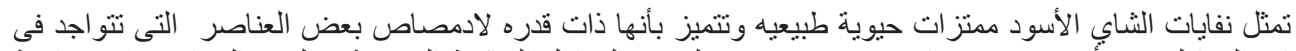

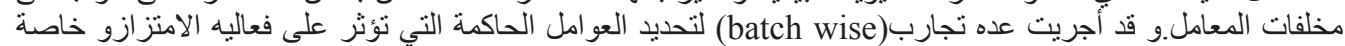

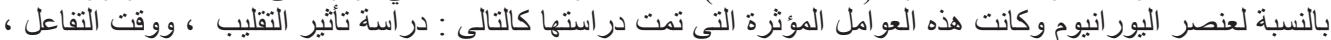

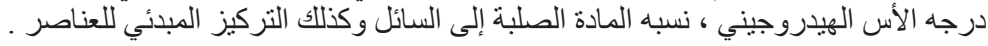

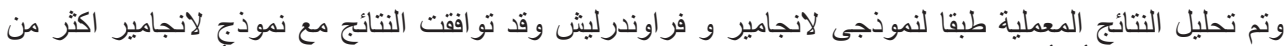

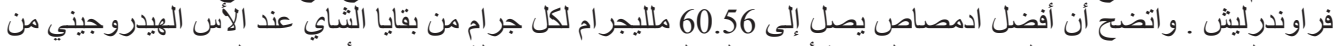

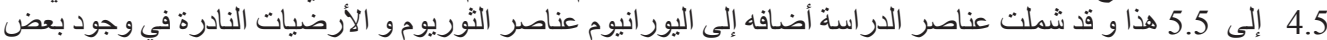

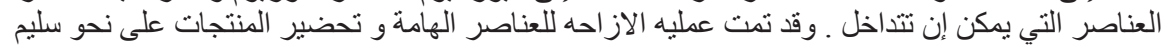

